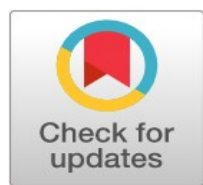

\title{
The role of employee's mindfulness and human resource development climate towards public leadership behavior-analyzing the moderating impact of emotional capital
}

\author{
Samara Bilal ${ }^{1 *}$, Muhammad Zia-ur-Rehman ${ }^{2}$ \\ 1,2 National Defence University, Islamabad, Pakistan
}

\author{
Keywords \\ Human resource \\ Development climate \\ Mindfulness \\ Public leadership behavior \\ Emotional capital \\ Received: 15 August 2017 \\ Accepted: 12 September 2017 \\ Published: 9 October 2017
}

\begin{abstract}
Present study examined the relationship between Human Resource Development (HRD) climate, mindfulness and public leadership behavior and how emotional capital increases the role of Human Resource Development Climate (HRDC) and mindfulness in public leadership behavior. Data were gathered from 252 respondents of 18 public universities of Islamabad and Rawalpindi. Random sampling technique was used. For analyzing the collected data, correlation and regression test were used. Findings of the study give clear picture of Public Leadership Behavior (PLB) in public universities of Pakistan. Study results proved that HRDC, mindfulness and PLB have the positive relationship which would further get enhanced by the role of emotional capital. For future researchers, this study also provides valuable findings and recommendations.
\end{abstract}

(C) 2017 The Author(s). Published by TAF Publishing.

\section{INTRODUCTION}

Study focuses on the potential influence of PLB and endeavors to identify the rationales for public leadership behaviors. In public universities, management satisfaction level is derived from their subordinates as well as from their own work performance. The main objective is to identify positive influences on PLB and inspect their implications for effective organizational performance. Senior managers play a vital role in accomplishing human resource policies because they affect employees' perceptions about their management and their behavior. As a result they support their leaders' behavior to elucidate the link between HRD and performance of the organization. For the public sector organizations, to deal with growing competitive pressures locally and globally, the presence of HRD climate is very essential (El-Ghalayini, 2016; Sabri \& Sami, 2014). HRD climate should be given a special attention in order to fill the existing knowledge gaps and to meet the organizational current and expected future needs.

Hyland, Lee, \& Mills (2015) finds that currently the idea of mindfulness is becoming popular among the organizational employees, leaders and psychologists. Mindfulness is an element of consciousness which has historically been associated with well-being. Organizations are always about their employees because employees are more than just capital. According to him it is about communicating and creating the meaning of personal relations. Susanne (2010) said that human, social and culture capitals are energized or boosted by emotional capital. Despite, there is a lack of scholars' interest in, how emotional capital can affect

\footnotetext{
* Corresponding author: Samara Bilal

${ }^{\dagger}$ Email: Samarajaved55@gmail.com
} 
the relationship between HRD climate, leader's behavior (Schmidt, 2010) and mindfulness (Silahtaroglu \& Vardarlier, 2016; Weick \& Sutcliffe, 2006) in the organization. Therefore this study observes the moderating impact of emotional capital on the relationship of HRD climate, mindfulness and PLB in public sector universities of Pakistan. In the competitive and complex global workplace emotional capital play an essential role in knowledge and self management for the organizations, educational institutions and companies (Zembylas, 2007).

Hence, there exists a gap in literature and present study in exploring the link of emotional capital with HRDC, employee's mindfulness and their PLB in the organization. Therefore this study investigates how emotional capital moderates the relationship between employees' mindfulness and HRD climate and their PLB? Present research is capable of contributing to a better understanding of leadership behavior in public universities. It develops a better understanding of their leadership behavior. It will also help future researchers to obtain thoughtful understanding to address the issue seriously in Pakistani perspective especially focusing on the public organizations to enhance the behavior and thus overall performance of the organizations.

\section{LITERATURE REVIEW}

\section{Employee's Mindfulness and PLB}

mindfulness is when a person attentively observes the mind process and keeps them in great regards. In a management area, mindfulness also contributes to create a better functional and more effective work place (Glomb, Duffy, Bono \& Yang, 2011). It is a thoughtful process towards the practices. Mindfulness plays pivotal role in career counseling of the individuals who are unsure about their goals (Susanne, 2010; Willy, 2017).

Influence on employees' attitudes, behaviors, perception and encouraging them to take lawful decision and take initiative to build their network at workplace (Momeni, 2009). Trust of the employees is increased when leader's behavior is recognized as reliable and trustworthy (Caldwell \& Hayes; 2010). In an organization, it is also necessary for an effective leadership to facilitate in collaboration. It may face changes and deviations that were not previously encountered. In such scenarios, it is important for the organization to be mindful. Hyland et al. (2015) explained that "The core business case for mindfulness is that the leader will be more effective if he/she is fully present on the job, he/she will make better decisions, and will work better with other people at the workplace."
H1: There is a significant relationship between mindfulness and PLB.

\section{HRDC and PLB}

HRD climate is the phenomenon that presents a concept of maximizing the employee's performance to achieve the profitable results. It is considered as the central part of supervisors' behaviors and attitudes towards their employees development (Akinyemi, 2014; Mahdieh, 2015). He further defines that in HRD climate the employees have insight about the organizational procedures, policies and practices that prevail in the organization.

Employees have the perception that they have organizational development environment in different organizational HR system and practices (Purohit \& Verma, 2013).

Public management personnel like managers, directors and supervisors have the strong tendency to implement the PLB at their workplace (Tummers \& Knies, 2014). PLB is having an extraordinary place within the organization. That's why working of public relation professionals are considered cross functionally, as boundary spanners (Choi \& Choi, 2009). Leaders facilitate the employees to maintain and develop a strong knit bond by uniting them. Leader's effectiveness acquires both a concern for the completion of task as well as ascertaining relationship with staff (Wang \& Shyu, 2008).

H2: There is a significant relationship between HRDC and PLB.

\section{Role of HRDC in Association with Emotional Capital and PLB}

Organizations are accountable for their staff, board of directors, clients, numerous financial supports, their ongoing tasks and customers. However arrangement for the numerous constituencies can direct to variation in the Leadership behaviors. Phipps \& Burbach (2010) narrated that in an organization, the hardest job for the leaders is to convince the diverse opinion groups on the future objectives. By doing this, differences are observed that how leaders behave in public organizations (Knies \& Leisink, 2014).

Accountability and openness of the employees and leader interaction are described by the open climate. Employee's emotional facet of work seems to be a source of pleasure and satisfaction rather than exploitation (Pulkkinen, 2015). When employees in the workgroup are performing their tasks, they develop mutual emotions among them. According to Susanne (2010) substantial successes of the organizations depend upon their emotional atmo- 
sphere. It includes their comfort level, rapport with colleagues, and concord with supervisors and deliberation about company matters. Researchers have done a very little study on this aspect and it has been mainly abandoned by them.

H3: There is a significant role of emotional capital in the relationship between HRDC and PLB.

\section{Role of Employee's Mindfulness in Association with Emotional Capital and PLB}

Employee's emotional capital facilitates their realistic and continual development in the long-term learning at workplace. Even it has profitable and crucial impact on the organization, society and for social and economical living too.

Mindfulness can also lead the senior leaders to advance their focus on their mindsets, emotional states, and how these two affect and how they interact with others. Intentionally long-term focus helps to improve leaders' flexibility and malleability (Schaufenbuel, 2014).

Leaders first know where to lead themselves than other people so leaders find out their full working potential before they lead others to discovering their full working potential. In an organization those employees who experience positive emotions make better decisions, they are more productive, creative, resilient, and have better interpersonal skills. There is study exploring the implication of emotional capital, mindfulness and PLB at workplace but still lot of work is required to find out emotional capital's impact on leader's behavior and employee's mindfulness.

H4: There is a significant role of emotional capital in the relationship between mindfulness and PLB.

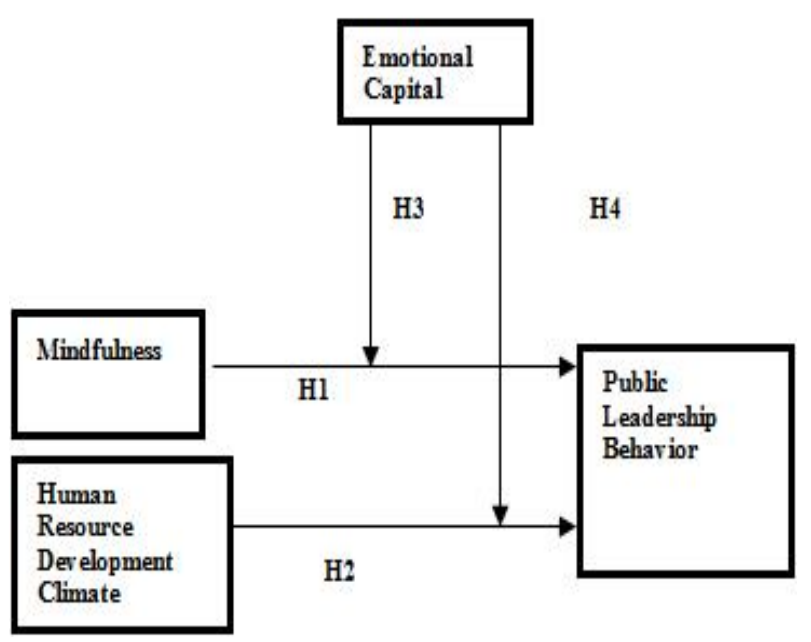

FIGURE 1. Conceptual framework

\section{RESEARCH METHODOLOGY}

Eighteen public universities in Islamabad and Rawalpindi as per Higher Education Commission (HEC) list were con sidered population, consisting of directors, deputy directors, and Managers, and were asked to complete a questionnaire alone. Population of this study was approx... 1200 as notified by universities management. This is an explanatory study, carried out to investigate the relationship of mindfulness and HRD climate that contour the behavior of leaders in public universities. Distributed questionnaires were 306 , from which only 270 responses were received back, and out of 270 only 252 were correctly filled one. While individuals are the unit of Analysis and from them data were gathered. The Random sampling technique was performed using the random number tables for the selection of sample. Collected data were analyzed by SPSS, 21 Version. Cross sectional study design was used as it is cost and time effective. This study is designed to attain the required objectives.

\section{Instrumentation}

Dimension of PLB was used to measure the variable PLB, which was developed by (Tummers \& Knies, 2014). The questionnaire measures four dimensions of PLB.

Toronto Mindfulness Scale (TMS) was used to measure the variable mindfulness, which was developed by (Lau et al., 2006). The questionnaire measures the two dimensions of mindfulness. HRD climate was used to measure the variable HRD climate, which was anticipated by (Rao \& Abraham, 1986). emotional capital inventory 360 was used to measure the variable emotional capital, which was developed by Martyn (2008). Questionnaire consists of 33 items and measures ten dimensions of emotional capital.

On five-point Likert scale from 1 (Strongly Disagree) to 5 (Strongly agree) responses were recorded from the participant. The scale was selected based on the instrument's validity; Cronbach's alpha reliability of PLB, mindfulness, HRD climate and emotional capital was 0.93, 0.84, 0.91 and 0.93 respectively.

\section{RESULTS}

\section{Frequency and Percentage of Personal Information}

According to results, frequency of males (171) is higher than females (83). Similarly the highest percentage lies between the age of 44 and above that is $39.8 \%$ and the lowest percentage of age lies in the category of 20 to 25 years i.e., 4.7\%. Respondents' working experience between 16-20 years has the highest percentage i.e., $42.9 \%$ and 1 to 5 years 
has the lowest percentage i.e., $0.8 \%$. Maximum percentage of respondents was $37.0 \%$, who had Master's qualification.

\section{Correlation Analysis}

PLB is found to be positively correlated to HRD climate ( $r$ $=0.484, p<0.01$ ) while emotional capital is significantly correlated to HRD climate ( $r=0.457, p<0.01)$. It also il- lustrates that mindfulness is positively correlated to HRD climate $(r=0.458, p<0.01)$. Emotional capital is positively correlated to PLB ( $r=0.447, p<0.01$ ), where as it showed that mindfulness is positively correlated to PLB $(r=0.420, p$ $<0.01$ ) and mindfulness is significantly correlated to emotional capital as well $(r=0.597, p<0.01)$.

TABLE 1. Variables correlation matrix $(N=252)$ regression analysis

\begin{tabular}{lcccc}
\hline \hline & HRDC & PLB & Emotional Capital & Mindfulness \\
\hline HRD climate & 1 & & & \\
PLB & $.484^{* *}$ & 1 & & \\
Emotional capital & $.457^{* *}$ & $.447^{* *}$ & 1 & 1 \\
Mindfulness & $.458^{* *}$ & $.420^{* *}$ & $.597^{* * *}$ & 1 \\
\hline **Correlation is significant at the 0.01 level (2-tailed).
\end{tabular}

Regression analysis was executed to inspect the relationship between the variables. Table 2 model summary of regression analysis for mindfulness with PLB.

In Table 2, to check the significance of the association between mindfulness and PLB linear regression analysis was carried out. Results show that all relationships are highly significant. The value of the beta coefficient was computed to be 0.420 representing positive relation between two variables. The value of $R^{2}=1.76$ reveal that change is brought in PLB due to MF. Hence it is proved that there is a positive relationship between mindfulness and PLB.

TABLE 2 . Model summary of regression analysis for mindfulness with PLB

\begin{tabular}{lcccccc}
\hline \hline $\mathbf{M}$ & $\boldsymbol{R}$ & $\boldsymbol{R}$ Square & \multicolumn{2}{c}{ Adjusted $\boldsymbol{R}$ Square } & Std. Error of the Estimate & \multicolumn{2}{c}{ Change Statistics } \\
\cline { 3 - 6 } & & & & $\boldsymbol{R}$ Square Change & $\boldsymbol{F}$ Change & Sig. $\boldsymbol{F}$ Change \\
\hline 1 & $.420^{a}$ & .176 & .173 & .5182 & .176 & 53.909 \\
\hline \hline a. Predictors: (Constant), CMF & & & & .000 \\
\hline
\end{tabular}

To check the significance of the association between HRD climate and PLB linear regression analysis was carried out in Table 3. Results show that all relationships are highly significant. The value of the beta $=0.468$ representing pos- itive relation between two variables. The value of $R^{2}=2.19$ reveal that change is brought in PLB due to HRD climate. Hence it supports the supposition that there is a positive relationship between HRD climate and PLB.

TABLE 3 . Model summary of regression analysis for HRD climate with PLB

\begin{tabular}{lcccccc}
\hline \hline $\mathbf{M}$ & $\boldsymbol{R}$ & $\boldsymbol{R}$ Square & Adjusted $\boldsymbol{R}$ Square & Std. Error of the Estimate & \multicolumn{2}{c}{ Change Statistics } \\
\cline { 3 - 7 } & & & & $\boldsymbol{R}$ Square Change & $\boldsymbol{F}$ Change & Sig. $\boldsymbol{F}$ Change \\
\hline 1 & $.468^{a}$ & .219 & .216 & .5045 & .219 & 70.663 \\
\hline \hline
\end{tabular}

a. Predictors: (Constant), HRDC

The regression analysis for emotional capital and mindfulness was carried out in Table 4 which shows that the value of $R^{2}$ reveals that 0.176 change is brought in PLB due to emotional capital and mindfulness. The $\beta$ value of 0.420 and 0.425 shows a positive impact of emotional capital and mindfulness on PLB. Hence it is proved that role of emotional capital has positive impact on the relationship between mindfulness and PLB. 
TABLE 4 . Model summary of regression analysis for emotional capital and mindfulness with PLB

\begin{tabular}{|c|c|c|c|c|c|c|c|}
\hline \multirow[t]{2}{*}{$\mathbf{M}$} & \multirow[t]{2}{*}{$\boldsymbol{R}$} & \multirow[t]{2}{*}{$R$ Square } & \multirow[t]{2}{*}{ Adjusted $R$ Square } & \multirow[t]{2}{*}{ Std. Error of the Estimate } & \multicolumn{3}{|c|}{ Change Statistics } \\
\hline & & & & & $R$ Square Change & $F$ Change & Sig. $F$ Change \\
\hline 1 & $.420^{a}$ & .176 & .173 & .5182 & .176 & 53.909 & .000 \\
\hline
\end{tabular}

a. Predictors: (Constant), CMF

b. Predictors: (Constant), CMF, MF_EC

The regression analysis for emotional capital and HRD climate was carried out in Table 5 which demonstrates the value of $R^{2}$ reveals that 0.327 change is brought in PLB, due to emotional capital and HRD climate. The beta value of
0.386 and 0.622 shows a positive impact of emotional capital and HRD climate on PLB. Hence it is hypothesized that there is a positive role of emotional capital on the relationship between HRD climate and PLB.

TABLE 5 . Model summary of regression analysis for HRD climate and emotional capital with PLB

\begin{tabular}{ccccccc}
\hline \hline $\mathbf{M}$ & $\boldsymbol{R}$ & $\boldsymbol{R}$ Square & \multicolumn{2}{c}{ Adjusted $\boldsymbol{R}$ Square } & Std. Error of the Estimate & \multicolumn{2}{c}{ Change Statistics } \\
\cline { 3 - 7 } & & & & $\boldsymbol{R}$ Square Change & $\boldsymbol{F}$ Change & Sig. $\boldsymbol{F}$ Change \\
\hline 1 & $.468^{a}$ & .219 & .216 & .5045 & .219 & 70.663 \\
2 & $.572^{b}$ & .327 & .322 & .4691 & .108 & 4000 \\
\hline \hline
\end{tabular}

a. Predictors: (Constant), HRDC

b. Predictors: (Constant), HRDC, HRDC_EC

\section{DSICUSSION}

Significant results were shown through detailed analysis; it's proposed that in an organization mindfulness has a positive impact on PLB. Results confirm that mindfulness is strongly and positively correlated with PLB. Results are in line with scholars (Hyland et al., 2015; Susanne 2010) who established the positive role of mindfulness in valuable PLB.

Glomb et al. (2011) also proposed that mindfulness plays a vital role in building of PLB. Study results verify the same trend and prove the H1 hypothesis. Study results confirm the proposition that mindfulness through decentering and curiosity, encourages and promotes the factors that boost PLB in an organization (Ndubisi, 2012).

It was hypothesized that HRD climate has a positive impact on PLB in an organization. Results show that HRD climate is strongly and positively correlated with PLB. Results are according to scholars (Akinyemi, 2014; Saraswathi, 2010) who confirmed the positive role of HRD climate in effective PLB. HRD climate plays a vital part in building a PLB and study's correlation matrix confirms it. This study has proved that employee's support their leaders' behavior to elucidate the link between HRD climate and organizational performance, which is substantiated by (Kuvaas \& Dysvik, 2010; Tummers \& Knies, 2014). The correlation matrix reveals that PLB has higher positive correlation with mindfulness. Moreover it was hypothesized that the emotional capital enhances the role of HRD climate on PLB.
Moderation Analysis results prove the $\mathrm{H} 3$ hypothesis that emotional capital positively moderates the relationship between mindfulness and PLB. There are several studies that have found the effect of emotional capital on the relationship between HRD climate, Leader's behavior (Hilgers, 2010; Schmidt, 2010, Stubbs \& Wolff, 2008) and mindfulness (Weick \& Sutcliffe, 2006; Baer, Smith, Hopkins \& Toney, 2006) in the organization.

However this study has taken all these variables in one study and has proven that emotional capital moderates the relationship between employees' mindfulness and HRD climate and their PLB.

It was hypothesized that the emotional capital enhances the role of HRD climate in PLB. Moderating regression analysis results prove the $\mathrm{H} 4$ hypothesis and it shows a considerable change in $R^{2}$ value.

\section{CONCLUSION}

Conclusively, HRD climate and mindfulness have positive impact on enhancing the PLB in public universities. It is suggested that universities that understand the importance of PLB should also understand the significance of HRD climate and mindfulness and how they enhance the leaders behavior. HRD climate and mindfulness develop an environment in the management that boosts leader's characteristics such as accountability, lawfulness, and ethical and network governance. Moreover this study concludes that 
emotional capital has a positive impact on PLB. It positively enhances the role of HRD climate and mindfulness in developing PLB. In order to successfully implement positive leadership behavior in the organization and to adopt an emotional capital conducive to effective behavior. Leaders need to reward employees for good team work, climate, creating curiosity and decentring. This study concludes that there is a positive relationship between HRD climate, mindfulness and PLB and their relationship would further get enhanced by the role of emotional capital.

\section{RECOMMENDATIONS}

It is suggested that the successful implementation of PLB in the organization and building of an emotional capital contributing to the effective HRD climate and mindfulness. The leaders are to be more visible and accessible about their beliefs and values. Leader's turn into resource for their employees and create a HRD climate so their subordinates experience safety and security. Leaders ensure that the emotional capital is the one that promotes general climate and mindfulness among employees. At present this study gives a logical picture of PLB in public universities of Pakistan and thus will help top management to boost their behaviors as well as it suggests that implementation of the emotional capital for the true identification and ultimate outcomes of the organization is required.

\section{REFERENCES}

Akinyemi, B.O. 2014. Human Resource Development Climate (HRDC) in the banking sector: General and gender perceptions. International Journal of Business \& Management, 9(10): 77-88. D0I: 10.5539/ijbm.v9n10p77

Baer, R.A., Smith, G.T., Hopkins, J., Krietemeyer, J., \& Toney, L. 2006. Using self-report assessment methods to explore facets of mindfulness. Assessment, 13(1): 27-45. DOI: 10.1177/1073191105283504

Caldwell, C., \& Hayes, L.A. 2010. Leadership, trustworthiness, and ethical stewardship. Journal of Business Ethics, 96(4): 497-512. DOI: $10.1007 / \mathrm{s} 10551-010-0489-y$

Choi, J., \& Choi, Y. 2009. Behavioral dimensions of public relations leadership in organizations. Journal of Communication Management, 13(4): 292-309. DOI: 10.1108/13632540911004588

El-Ghalayini, Y. 2016. The effects of high performance work system on employee attitudes: A study of international organi-

tion. Journal of Administrative \& Business Studies, 2(5): 248-263. DOI: 10.20474/Jabs-2.5.1

Glomb, T. M., Duffy, M.K., Bono, J.E., \& Yang, T. 2011. Mindfulness at work: Research in personnel and human resources management. Bingley, U.K: Emerald Group Publishing Limited.

Hilgers, M. 2010. The three anthropological approaches to neoliberalism. International Social Science Journal, 61(202): 351-364.

Hyland, P.K., Lee, R.A., \& Mills, M.J. 2015. Mindfulness at work: A new approach to improving individual and organizational performance. Industrial \& Organizational Psychology, 8(4): 576-602. DOI: 10.1017/iop.2015.41

Knies, E., \& Leisink, P. 2014. Leadership behavior in public organizations: A study of supervisory support by police and medical center middle managers. Review of Public Personnel Administration, 34(2): 108-127.

DOI: $10.1177 / 0734371 \times 13510851$

Kuvaas, B., \& Dysvik, A. 2010. Exploring alternative relationships between perceived investment in employee development, perceived supervisor support and employee outcomes. Human Resource Management Journal, 20(2): 138-156. DOI: $10.1111 / \mathrm{j} .1748-8583.2009 .00120 . x$

Lau, M.A., Bishop, S.R., Segal, Z.V., Buis, T., Anderson, N.D., Carlson, L., \& Devins, G. 2006. The Toronto mindfulness scale: Development and validation. Journal of Clinical Psychology, 62(12): 1445-1467. D0I: 10.1002/jclp.20326

Martyn L.N. 2008. Emotional capital inventory 360. URL: goo.gl/w9Xnau. Last accessed on 23 April 2017.

Mahdieh, 0. 2015. Interaction between communication and organizational conflict and its relationship with performance. International Journal of Business and Administrative Studies, 1(2): 54-60. DOI: 10.20469/ijbas.10002-2

Momeni, N. 2009. The relation between managers' emotional intelligence and the organizational climate they create. Public Personnel Management, 38(2): 35-48. D0I: 10.1177/009102600903800203

Ndubisi, N.O. 2012. Mindfulness, reliability, pre-emptive conflict handling, customer orientation and outcomes in Malaysia's healthcare sector. Journal of Business Research, 65(4): 537-546. DOI: 10.1016/j.jbusres.2011.02.019 
Phipps, K.A., \& Burbach, M.E. 2010. Strategic leadership in the nonprofit sector: Opportunities for research. Journal of Behavioral \& Applied Management, 11(2): 137-140.

Purohit, B., \& Verma, R.K. 2013. A study of human resource development climate in government health centres in India.

Journal of Health Management, 15(3): 431-443. DOI: 10.1177/0972063413491878

Pulkkinen, T. 2015. The postmodern and political agency. New York, NY: Willy \& Sons.

Rao, T.V., \& Abraham, E. 1986. HRD climate in organizations. In T.V. Rao (Eds.), Readings in human resource develop- ment, Oxford, UK: IBH Publishing.

Sabri, P.S., \& Sami, P. 2014. Human resource development climate and organizational citizenship behavior: A study on the mediating effects of perceived organizational support in the manufacturing sector of Pakistan. Science International, 26(1): 391-402.

Saraswathi, S. 2010. Human resources development climate: An empirical study. International Journal of Innovation, Management \& Technology, 1(2): 174-180.

Schaufenbuel, K. 2014. Bringing mindfulness to the workplace. URL: goo.gl/KeJTez. Last accessed on 15 June 2016.

Schmidt, M.J. 2010. Is there a place for emotions within leadership preparation programmes? Journal of Educational

Ad- ministration, 48(5): 626-641. DOI: /10.1108/09578231011067776

Silahtaroglu, G., \& Vardarlier, P. 2016. Leaders impact on organizational behavior: A text mining study on universities in

Turkey. International Journal of Business and Administrative Studies, 2(2): 52-56. D0I: /10.20469/ijbas.2.10005-2

Stubbs Koman, E., \& Wolff, S.B. 2008. Emotional intelligence competencies in the team and team leader: A multi-level exam- ination of the impact of emotional intelligence on team performance. Journal of Management Development, 27(1): $\quad$ 55-75. DOI: 10.1108/02621710810840767

Susanne, H. 2010. Utilizing the concept of "Emotional Capital"-"Family" as an image and a narrative in 20th-century corporate communications. Paper presented at the for the European Business History Association, Glasgow, Scotland.

Virkki, T. 2007. Emotional capital in caring work. In E.J. Charmine, N. Härtel, M. Neal, A. Ashkanasy \& J. Wilfred Zerbe (Eds.), Functionality, intentionality and morality, New York, NY: Emerald Group Publishing Limited.

Tummers, L., \& Knies, E. 2014. The public leadership questionnaire: The development and validation of five dimensions of public leadership behaviors. Public Administration, 94(2): 433-451. D0I: 10.1111/padm.12224

Wang, D.S., \& Shyu, C.L. 2008. Will the strategic fit between business and HRM strategy influence HRM effectiveness and organizational performance? International Journal of Manpower, 29(2): 92-110. DOI: 10.1108/01437720810872677 Willy, S. 2017. Analysis of financial ratios to measure the company's performance in the sectors of consumer goods at Pt.

Nippon Indosari Corpindo, Tbk and Pt. Mayora Indah, Tbk. International Journal of Business and Economic Affairs, 2(1): 45-51. DOI: 10.24088/ijbea-2017-21006

Weick, K.E., \& Sutcliffe, K.M. 2006. Mindfulness and the quality of organizational attention. Organization Science, 17(4): 514-524. DOI: 10.1287 /orsc.1060.0196

Zembylas, M. 2007. Emotional capital and education: Theoretical insights from Bourdieu. British Journal of Educational Studies, 55(4): 443-463. DOI: 10.1111/j.1467-8527.2007.00390.x

Zivnuska, S., Kacmar, K.M., Ferguson, M., \& Carlson, D.S. 2016. Mindfulness at work: Resource accumulation, well-being, and attitudes. Career Development International, 21(2): 106-124. DOI: 10.1108/cdi-06-2015-0086 